\section{RMD Open}

Rheumatic \&

Musculoskeletal Diseases

To cite: Turk M, Hayworth J, Nevskaya T, et al. The frequency of uveitis in patients with adult versus childhood spondyloarthritis. RMD Open 2020;6:e001196. doi:10.1136/ rmdopen-2020-001196

- Supplemental material is published online only. To view please visit the journal online (http://dx.doi.org/10.1136/rmdo pen-2020-001196)

Received 4 February 2020 Revised 4 May 2020 Accepted 1 August 2020
Check for updates

(c) Author(s) (or their employer(s)) 2020. Re-use permitted under CC BY-NC. No commercial re-use. See rights and permissions. Published by BMJ.

${ }^{1}$ University of Western Ontario, London, Canada

${ }^{2}$ Family Medicine, University of Toronto, Toronto, Canada

${ }^{3}$ Medicine, Division of

Rheumatology, Western University, London, Canada

Correspondence to Janet Pope; janet.pope@sjhc. Iondon.on.ca

\title{
The frequency of uveitis in patients with adult versus childhood spondyloarthritis
}

\author{
Matthew Turk, ${ }^{1}$ Jacqueline Hayworth, ${ }^{2}$ Tatiana Nevskaya, ${ }^{3}$ Janet Pope $\mathbb{1}^{3}$
}

\section{ABSTRACT}

Objectives This meta-analysis investigated the frequency of ocular involvement in childhood and adult spondyloarthritis (SpA).

Methods A systematic review of the literature was conducted. Medline, Web of Science and Cochrane databases were searched upto October 2018 identifying publications related to $\mathrm{SpA}$, including ankylosing spondylitis (AS) with ocular conditions (OC) (uveitis, iritis, retinitis, chorioretinitis and other ocular involvement). The rates of OC were extracted and random effects models estimated their frequency. Heterogeneity was evaluated using $\mathrm{I}^{2}$. Inclusion criteria were studies in SpA of either children or adults who included a frequency of $\mathrm{OC}$.

Results 3164 studies were identified, and 41 analysed which included frequencies of uveitis/iritis. Other $\mathrm{OC}$ were too infrequent to analyse. A pooled random effects model showed that the prevalence of uveitis was $24 \%$ in adult AS (23 studies, 11943 patients), $10 \%$ in adult psoriatic arthritis (PsA) (9 studies, 1817) and $17 \%$ in undifferentiated adult SpA (9 studies, 6568 patients). In juveniles with AS, the prevalence of uveitis was $27 \%$ (8 studies, 927 patients), in juvenile PsA it was $16 \%$ (5 studies, $\mathrm{N}=498$ ) and in juvenile undifferentiated SpA, uveitis occurred in 7\% (2 studies, 1531 patients). In all evaluated SpA subgroups, there were no statistical differences in the frequency of uveitis between juveniles and adults. Conclusions Uveitis in adult versus child-onset $\mathrm{SpA}$ is similar in AS but more common in adult-onset undifferentiated $\mathrm{SpA}$, and less frequent in adult-onset PsA compared to childonset PsA, but the differences were not significant.

\section{INTRODUCTION}

Adult spondyloarthritis ( $\mathrm{SpA})$ is characterised by abnormal bone overgrowth and inflammatory erosive osteopenia in the spine. ${ }^{12}$ It usually begins under the age of 40 and is more common in men. SpA may be associated with psoriasis and psoriatic arthritis (PsA), inflammatory bowel disease, reactive arthritis, enthesitis, and ocular features such as acute anterior iritis, and chronic uveitis (anterior or posterior, unilateral or bilateral). ${ }^{3}$ Juvenile SpA (JSpA) onsets in children under 16 years, and at the beginning of the disease, it may present with more peripheral enthesopathies and arthritis than adult SpA. ${ }^{4}$ Children with juvenile idiopathic arthritis have more ocular involvement than many adultonset types of inflammatory arthritis. Due to

\section{Key messages}

In some forms of childhood arthritis compared to adult arthritis, uveitis is more common (such as oligoarticular JIA). However, the prevalence of uveitis in child-onset versus adult-onset seronegative spondyloarthritis may differ.

- This meta-analysis compared the frequency of uveitis in spondyloarthritis in adults and children including the spectrum of $\mathrm{AS}$, undifferentiated SpA and PsA.

- It appears that the frequency of uveitis is not statistically different in adult-onset versus child-onset ankylosing spondylitis, psoriatic arthritis and undifferentiated spondyloarthritis.

differences in clinical presentation, we wondered if adult SpA and JSpA may have different frequencies of uveitis.

Uveitis in SpA is usually acute unilateral anterior iritis, which is associated with Human Leucocyte Antigen B27 (HLA-B27) positivity. However, in PsA, ocular involvement is less common than in ankylosing spondylitis (AS) and tends to present as bilateral posterior uveitis. ${ }^{5}$ Despite reductions in uveitis with treatment such as monoclonal antibodies against Tumor Necrosis Factor (TNF), some patients experience decreased vision, blindness, cataracts and glaucoma as complications of their disease and/or treatment. ${ }^{6}$

We conducted a systematic review of the literature and meta-analysis of ocular manifestations to determine their frequency in adult and juvenile seronegative SpA. Previous efforts have determined the prevalence of uveitis in SpA; however, children were not included in this study. ${ }^{7}$ The prevalence of uveitis in JSpA has also been reported but did not include adult-onset SpA. ${ }^{8}$

\section{METHODS}

\section{Study selection}

The protocol of ocular conditions (OC) in rheumatic conditions was registered at 
clintrials.gov with the trial ID NCT03753893. Using the literature search, we studied several questions with respect to ocular manifestations of rheumatic diseases, and for this question, we compared adult versus juvenile onset of uveitis and other ocular manifestations in SpA. Search terms related to ocular complications in adult and pediatric seronegative $\mathrm{SpA}$ are provided in online supple mental table 1. Web of Science, Medline and Cochrane were searched from their commencement (1990, 1966 and 1991, respectively) to October 2, 2018. Studies were reviewed if they mentioned a prevalence of OC in adult and/or paediatric patients. Publications were included if they included any SpA category such as AS, PsA and undifferentiated SpA.

\section{Inclusion criteria}

Studies were included if they provided the frequency, prevalence or incidence of ocular manifestations in the diagnoses of interest (SpA spectrum arthritis in adults and children). Review articles, case reports where all patients experienced the same ocular comorbidity and if the study included less than 20 patients were reasons to be excluded. If the study population was repeated in two or more publications, the most recent or largest sample size study was included in order to eliminate double counting patients. The STROBE (Strengthening the Reporting of Observational Studies in Epidemiology) checklist was used to assess the quality of included studies. ${ }^{9}$ Differences between adults and children overall for SpA and within the subsets of AS, PsA and undifferentiated SpA were evaluated for significance using $\chi^{2}$ tests. $^{10}$

\section{Data extraction}

Data such as the authors, study year and location, sample size and frequency of each ocular complication (primarily uveitis) within the SpA diagnoses and adult or child onset were obtained from each paper. If a study included a paediatric and adult subset, they were treated independently for the purposes of data extraction.

\section{Statistics}

Forest plots were created with a 95\% CI with Wilson's score method, from the frequencies of OC extracted from the data. Variance was used to create study weights using a random effects model to account for differences in study size and quality. ${ }^{11}$ I-squared and tau-squared tests were used to determine heterogeneity within each forest plot. Publication bias was estimated by the symmetry of funnel plots.

\section{RESULTS}

The search process identified 3164 articles, of which 41 were eligible for inclusion (figure 1). These 41 articles reported on the frequency of uveitis. Online supplemental table 2 shows the publications that were included and

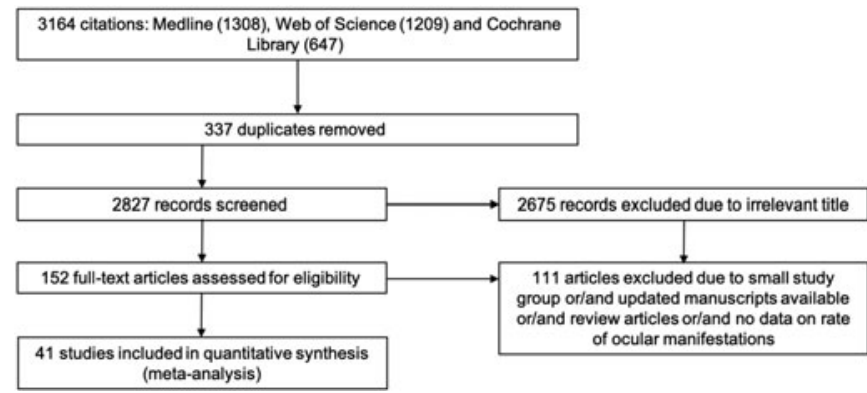

Figure 1 Diagram of the search results.

whether they were for adult or paediatric and AS or SpA or PsA. The table also provides the country, total sample and number with ocular involvement and the STROBE score. A pooled random effects model showed that the prevalence of uveitis was $24 \%(20-27 \%)$ in adult AS (23 studies, $\mathrm{N}=11943$ patients), $10 \%(7-14 \%)$ in adult PsA (9 studies, $\mathrm{N}=1817)$ and $17 \%(10-24 \%)$ in undifferentiated adult SpA (9 studies, 6568 patients) (figure 2). In juveniles with AS, the prevalence of uveitis was 27\% (16-39\%) (eight studies, 927 patients). In child-onset PsA (JPsA), uveitis occurred in 16\% (10-21\%) (five studies, $\mathrm{N}=498$ ), and in juvenile undifferentiated $\mathrm{SpA}$, uveitis had a frequency of $7 \%$ (1-12\%) (two studies, $\mathrm{N}=1531$ ) (figure 3).

The differences in frequency of uveitis in adults versus child-onset SpA spectrum diseases were not significantly different between AS and JAS ( $\mathrm{p}=0.891$ ), PsA and JPsA $(\mathrm{p}=0.732)$ and between SpA and JSpA $(\mathrm{p}=0.751)$.

A random effects model was used to generate forest plots as heterogeneity for several of the prevalence estimates was high. Publication bias was mostly negligible except in adult AS (online supplemental figure 1A).

\section{DISCUSSION}

These results provide comparison of patients (adults vs children) for AS, undifferentiated SpA and PsA and illustrate that the frequency is not statistically different in child versus adult onset but varies between the disease types. PsA has less uveitis than AS and more posterior uveitis than AS and undifferentiated SpA.

As with many studies of this nature, there are several limitations, chiefly development and standardisations of novel treatments during the period of data collection. These treatments may have an impact on the prevalence of ocular comorbidities as some are treated in conjunction with their underlying disease. ${ }^{12} 13$ The frequency of uveitis varied between studies, and definitions were not standardised. There was heterogeneity in several of the Forest plots. Disease duration and length of follow-up varied between cohorts, and so the life-long risk of child onset SpA may or may not be higher than what was found. For example, if most uveitis onsets early in disease, then younger age may 
A.

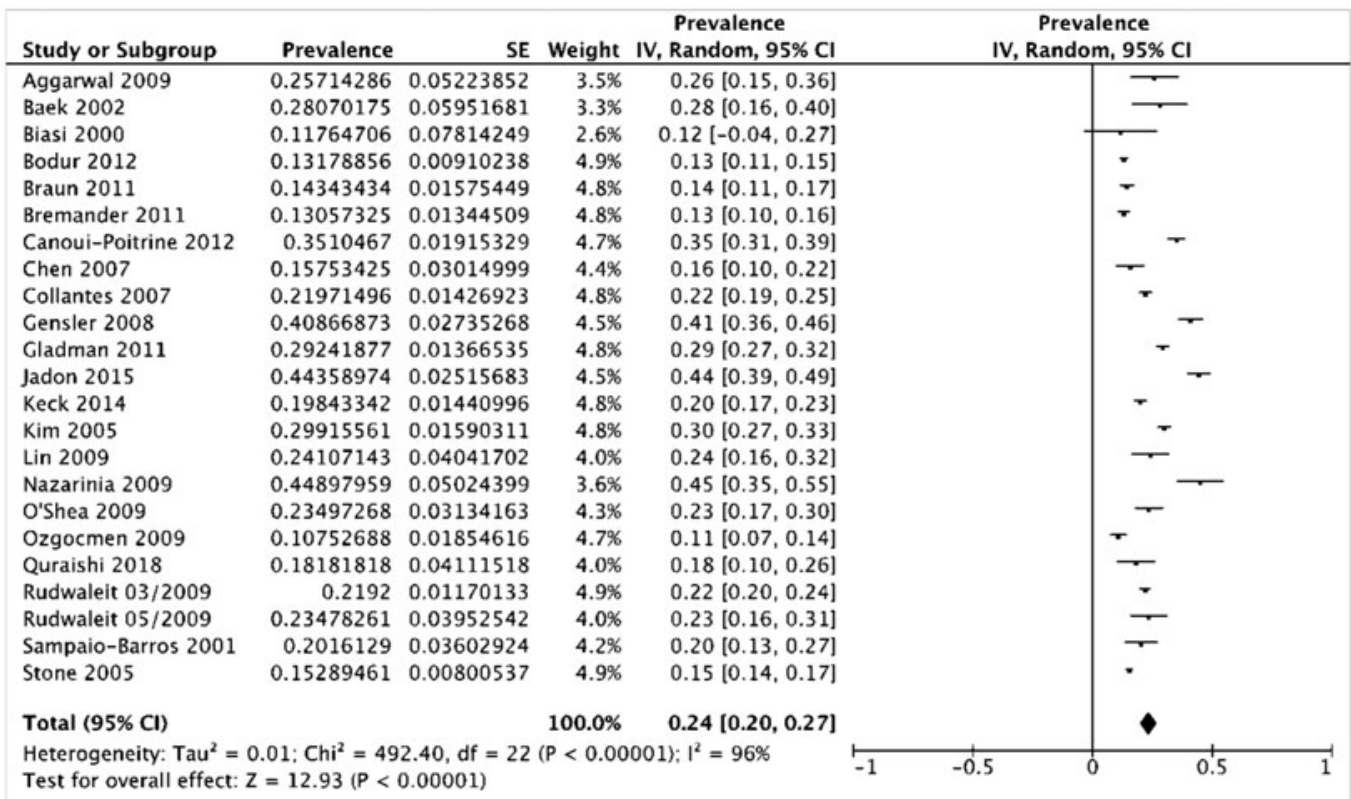

B.

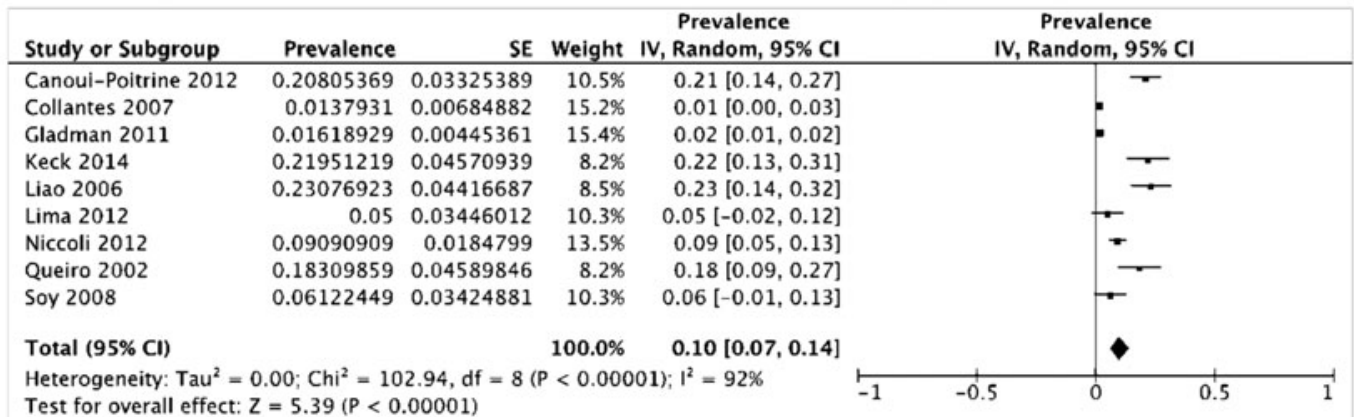

C.

\begin{tabular}{|c|c|c|c|c|c|c|}
\hline \multirow{2}{*}{$\begin{array}{l}\text { Study or Subgroup } \\
\text { Collantes } 2007\end{array}$} & \multirow{2}{*}{$\begin{array}{r}\text { Prevalence } \\
0.09268293\end{array}$} & \multirow{2}{*}{ SE } & \multirow{2}{*}{$\begin{array}{r}\text { Weight } \\
11.1 \%\end{array}$} & \multirow{2}{*}{$\begin{array}{c}\begin{array}{c}\text { Prevalence } \\
\text { IV, Random, 95\% CI }\end{array} \\
0.09[0.05,0.13]\end{array}$} & \multicolumn{2}{|c|}{$\begin{array}{c}\text { Prevalence } \\
\text { IV, Random, } 95 \% \mathrm{CI} \\
\end{array}$} \\
\hline & & & & & & 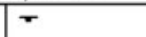 \\
\hline Gallinaro 2010 & 0.23981324 & 0.00879648 & $11.5 \%$ & $0.24[0.22,0.26]$ & & - \\
\hline García-Vicuña 2017 & 0.03118908 & 0.00767471 & $11.5 \%$ & $0.03[0.02,0.05]$ & & - \\
\hline Gladman 2011 & 0.17204301 & 0.0391364 & $10.1 \%$ & $0.17[0.10,0.25]$ & & $=$ \\
\hline Keck 2014 & 0.26315789 & 0.04517869 & $9.7 \%$ & $0.26[0.17,0.35]$ & & $\rightarrow$ \\
\hline Kumar 2001 & 0.18181818 & 0.08223037 & $7.0 \%$ & $0.18[0.02,0.34]$ & & 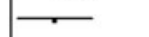 \\
\hline Liao 2006 & 0.30952381 & 0.07133403 & $7.8 \%$ & $0.31[0.17,0.45]$ & & \\
\hline Quraishi 2018 & 0.11320755 & 0.04352219 & $9.8 \%$ & $0.11[0.03,0.20]$ & & 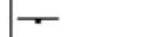 \\
\hline Rudwaleit 03/2009 & 0.15789474 & 0.03741151 & $10.2 \%$ & $0.16[0.08,0.23]$ & & $\rightarrow$ \\
\hline Sampaio-Barros 2013 & 0.1849826 & 0.0086585 & $11.5 \%$ & $0.18[0.17,0.20]$ & & * \\
\hline \multirow{2}{*}{\multicolumn{5}{|c|}{$\begin{array}{l}\text { Total }(95 \% \mathrm{Cl}) \\
\text { Heterogeneity: } \text { Tau }^{2}=0.01 ; \mathrm{Chi}^{2}=376.78, \mathrm{df}=9(\mathrm{P}<0.00 \% \quad \mathbf{0 . 1 7}[\mathbf{0 . 1 0}, \mathbf{0 . 2 4}] \\
\text { Test for overall effect: } \mathrm{Z}=4.87(\mathrm{P}<0.00001)\end{array}$}} & & \\
\hline & & & & & -0. & 0 \\
\hline
\end{tabular}

Figure 2 Forest plot analysis: prevalence of ocular manifestations in adults with ankylosing spondylitis (A), psoriatic arthritis (B) and undifferentiated spondyloarthritis (C). 
A.

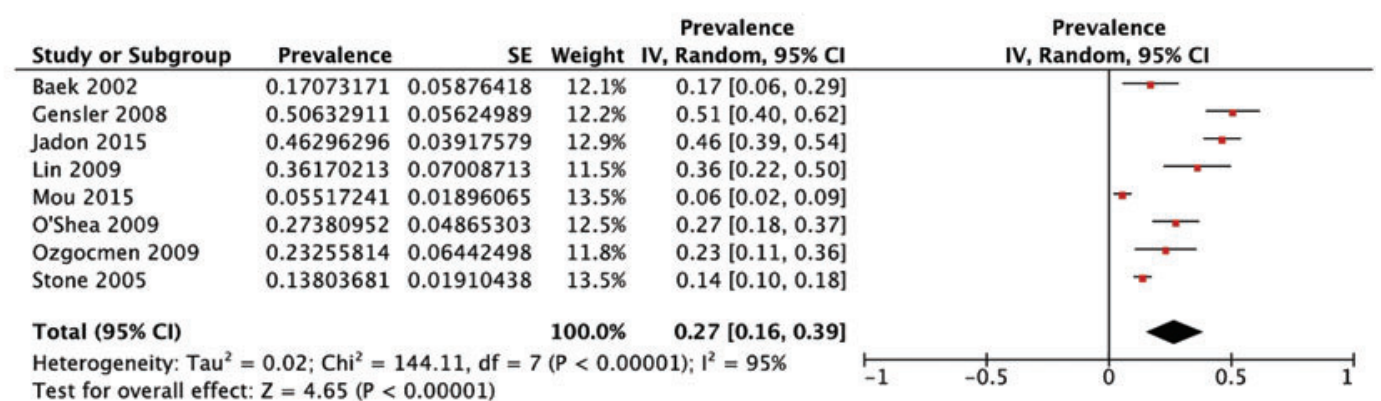

B.

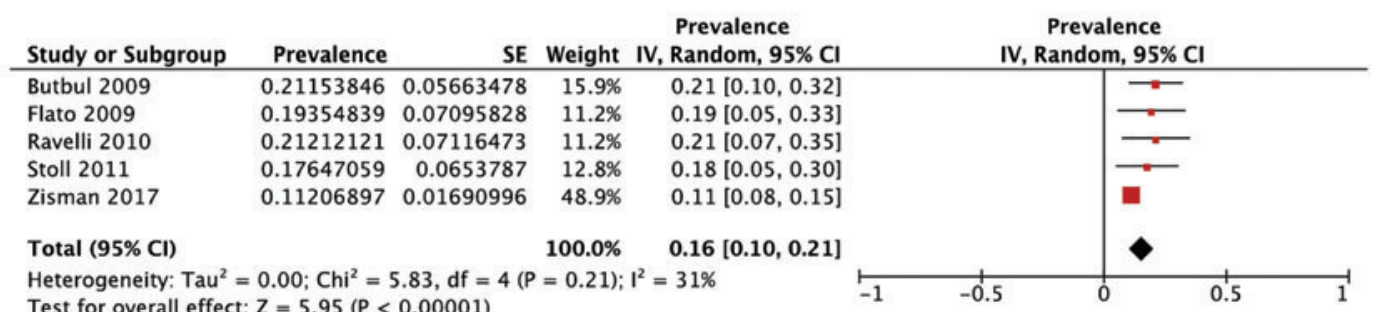

C.

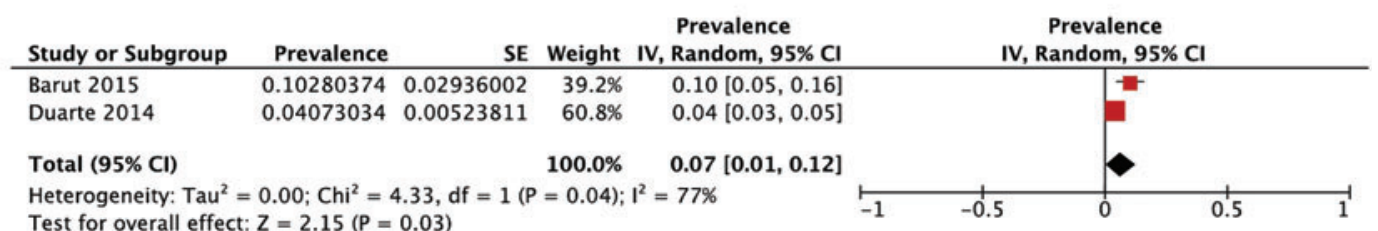

Figure 3 Forest plot analysis: prevalence of ocular manifestations in children with ankylosing spondylitis (A), psoriatic arthritis (B) and with juvenile undifferentiated spondyloarthritis (C).

not be an important confounder. Whereas if there is a steady linear increase in the first iritis over years, then it could be underestimated in younger patients, which is unlikely. ${ }^{14}$ There was no standardised followup period between studies.

The search did not include EMBASE and so some articles may have been missed if they were only published in journals that are not included in the other databases that were searched. However, since there were no differences between the frequency of uveitis in SpA in adults versus children, it is unlikely that there would be enough articles with large sample sizes that would change the conclusions. We did not search enthesitis-related arthritis and so in particular may have missed child-onset SpA studies. A recent study (published after our search) demonstrated that in National Pediatric Database in Germany (a national registry with nearly 25000 juvenile inflammatory arthritis (JIA) patients), $7.4 \%$ of children with enthesitis-related arthritis were diagnosed with uveitis (53). This supports our results where $7 \%$ of PSpA had uveitis. Another limitation to this metaanalysis is potential publication bias as negative studies (or papers with low frequency of ocular involvement) are likely not published. As such, reporting of OC in published literature may be an underestimate or overestimate of reality (ascertainment may not have been verified, recall bias may have occurred for those with long disease duration or misdiagnosis of acute anterior iritis may have happened in some patients). Another limitation is the lack of disease outcome or activity, other comorbidities and cofounders. In addition, we were unable to estimate the incidence of uveitis, but instead used a cumulative prevalence (ever present uveitis or overall frequency). 
The prevalence of uveitis was determined to be $\sim 33 \%$ in SpA, but their study excluded juvenile spondylopathies. ${ }^{7}$ Our study found the prevalence to be lower (one in four whereas the other study suggested it was one in three).

\section{CONCLUSIONS}

There were no statistical differences between adult and childhood onset of uveitis in SpA. AS was reported to have the most uveitis, then undifferentiated SpA and PsA had the least.

Acknowledgements We would like to thank Brad Dishan for his help in designing the search strategy. We would also like to acknowledge the abstract by Tinazzi et al, presented at EULAR in 2019. ${ }^{15}$

Contributors $\mathrm{JH}$ and MT were involved in literature search, study design and manuscript writing. TN was involved in statistical analyses and manuscript writing. JP was involved in study design, statistical analyses and manuscript writing.

Funding The authors have not declared a specific grant for this research from any funding agency in the public, commercial or not-for-profit sectors.

Competing interests None declared.

Patient consent for publication Not required.

Provenance and peer review Not commissioned; externally peer reviewed.

Data availability statement All data relevant to the study are included in the article or uploaded as supplementary information.

Supplemental material This content has been supplied by the author(s). It has not been vetted by BMJ Publishing Group Limited (BMJ) and may not have been peerreviewed. Any opinions or recommendations discussed are solely those of the author(s) and are not endorsed by BMJ. BMJ disclaims all liability and responsibility arising from any reliance placed on the content. Where the content includes any translated material, BMJ does not warrant the accuracy and reliability of the translations (including but not limited to local regulations, clinical guidelines, terminology, drug names and drug dosages), and is not responsible for any error and/or omissions arising from translation and adaptation or otherwise.

Open access This is an open access article distributed in accordance with the Creative Commons Attribution Non Commercial (CC BY-NC 4.0) license, which permits others to distribute, remix, adapt, build upon this work non-commercially, and license their derivative works on different terms, provided the original work is properly cited, appropriate credit is given, any changes made indicated, and the use is non-commercial. See: http://creativecommons.org/licenses/by-nc/4.0/.
ORCID iD

Janet Pope http://orcid.org/0000-0003-1479-5302

\section{REFERENCES}

1 Reveille JD, Weisman MH. The epidemiology of back pain, axial spondyloarthritis and HLA-B27 in the United States. Am J Med Sci 2013;345:431-6.

2 Smith JA. Update on ankylosing spondylitis: current concepts in pathogenesis. Curr Allergy Asthma Rep 2015;15:489.

3 Stolwijk C, Essers I, van Tubergen A, et al. The epidemiology of extra-articular manifestations in ankylosing spondylitis: a population-based matched cohort study. Ann Rheum Dis 2015;74:1373-8.

4 Lin Y-C, Liang T-H, Chen W-S, et al. Differences between juvenile-onset ankylosing spondylitis and adult-onset ankylosing spondylitis. J Chin Med Assoc 2009;72:573-80.

5 Cantini F, Nannini C, Cassarà E, et al. Uveitis in spondyloarthritis: an overview. J Rheumatol Suppl 2015;93:27-9.

6 Durrani OM, Tehrani NN, Marr JE, et al. Degree, duration, and causes of visual loss in uveitis. Br J Ophthalmol 2004;88:1159-62.

7 Zeboulon N, Dougados M, Gossec L. Prevalence and characteristics of uveitis in the spondyloarthropathies: a systematic literature review. Ann Rheum Dis 2008;67:955-9.

8 Hayworth JL, Turk MA, Nevskaya T, et al. The frequency of uveitis in patients with juvenile inflammatory rheumatic diseases. Joint Bone Spine 2019;86:685-90.

9 von Elm E, Altman DG, Egger M, et al. The strengthening the reporting of observational studies in epidemiology (STROBE) statement: guidelines for reporting observational studies. Lancet 2007;370:1453-7.

10 Campbell I. Chi-squared and Fisher-Irwin tests of two-by-two tables with small sample recommendations. Stat Med 2007;26:3661-75.

11 DerSimonian R, Laird N. Meta-analysis in clinical trials revisited. Contemp Clin Trials 2015;45:139-45.

12 Jaffe GJ, Dick AD, Brézin AP, et al. Adalimumab in patients with active noninfectious uveitis. New England J Med 2016;375:932-43.

13 Mitulescu T-C, Trandafir M, Dimăncescu M-G, et al. Advances in the treatment of uveitis in patients with spondyloarthritis - is it the time for biologic therapy? Rom J Ophthalmol 2018;62:114-22.

14 Feldtkeller E, Khan MA, van der Heijde D, et al. Age at disease onset and diagnosis delay in HLA-B27 negative vs. positive patients with ankylosing spondylitis. Rheumatol Int 2003;23:61-6.

15 Tinazzi I, Variol A, Marchetta A, et al. SAT0351 IBIS-Q (IBD identification of spondyloarthritis questionnaire): a new tool to detect spondyloarthritis in inflammatory bowel disease patients. Saturday, 15 June 2019 [Internet] BMJ Publishing Group Ltd and European League Against Rheumatism. 2019. 1255.2-1256. Available http://ard. bmj.com/lookup/doi/10.1136/annrheumdis-2019-eular.5887 (accessed 27 Jul 2020) 